\title{
The Basic Electrical Rhythm of the Duodenum in Normal Human Subjects and in Patients with Thyroid Disease *
}

\author{
James Christensen, Harold P. Schedl, and James A. Clifton \\ (From the Gastroenterology Research Laboratory, the Department of Internal Mcdicine, Statc \\ University of Iowa College of Medicine, Iozva City, Iozva)
}

The smooth muscle of the small intestine has a characteristic pattern of electrical activity. This pattern has been observed in vivo in the dog (1-9), rabbit $(5,10)$, cat $(11)$, and in man $(5,7,8,12)$ and in vitro in excised intestinal segments from the cat $(4,10,13)$, rabbit $(14,15)$, and other species. Animal studies have shown that it consists of two wave forms: 1) a slow sinusoidal wave, the slow wave or basic electrical rhythm (BER), and 2) intermittent bursts of fast spikes superimposed on the BER. The BER is generated at a remarkably constant rate by the longitudinal layer of the smooth muscle (10), and its frequency determines the upper limit of frequency of the rhythmic segmenting muscle contractions. The fast spikes superimposed on the BER are often associated with contractions.

Previous investigations of the BER in man were done in ileal stomas or in the upper small intestine during abdominal operations. We have devised a method for recording duodenal electrical activity in ambulatory human subjects. The present study defines the range of duodenal BER frequencies in man under normal conditions and in some abnormal ones, and for the first time establishes the relationship between this frequency and the metabolic rate.

* Submitted for publication December 9, 1963; accepted April 22, 1964.

Other reports: Christensen, J., H. P. Schedl, and J. A. Clifton. Electrical activity of the human duodenum. Clin. Res. 1962, 10, 291. Christensen, J., H. P. Schedl, and J. A. Clifton. The duodenal electrical activity in normal subjects and in patients with thyroid disease. Clin. Res. 1963, 11, 291.

Supported in part by a U. S. Public Health Service training grant (5-T1-AM-5390-01) and research grant (AM-02534-05) from the National Institute of Arthritis and Metabolic Diseases.

\section{Methods}

Electrode. Duodenal electrical activity is recorded with a silver silver-chloride $\mathrm{KCl}$ salt-bridge electrode (Figure 1). A 1-meter segment of shielded coaxial cable with an outside diameter of $5 \mathrm{~mm}$ is fitted with a threaded nylon hub that is screwed into a hollow nylon capsule. The filament of the cable is soldered to a chloride-treated silver wire that protrudes into the capsule chamber. The chamber is filled with $3 \mathrm{M} \mathrm{KCl}$ through a hole $1 \mathrm{~mm}$ in diameter that leads from the chamber to the outside of the capsule to complete the electrical circuit. This hole is plugged with cotton. A $1-\mathrm{ml}$ waterfilled latex balloon attached to the capsule on the side opposite the hole communicates with a $1.7 \mathrm{~mm}$ inside diameter water-filled polyethylene tube that is tied loosely to the length of cable.

Subjects and patients. Students from the University of Iowa and inmates of the Iowa State Penitentiary served as normal volunteers. All 37 subjects were in good health, and none had a history of gastrointestinal or thyroid disease. Laboratory evaluation of thyroid and gastrointestinal function was not done. We studied 24 patients who had been referred to University of Iowa Hospitals for evaluation of thyroid function. A diagnosis of hypothyroidism, hyperthyroidism, or the euthyroid state was established in each on the basis of clinical evaluation and appropriate laboratory tests.

Method of study. The electrode assembly was passed into the duodenum with fluoroscopic guidance and the cable connected to the a.c. input of a Sanborn electrocardiogram (EKG) preamplifier (model 150-1600).1 The other side of the input was connected to a standard EKG skin electrode placed on the abdomen near the umbilicus. The position of the skin electrode was varied slightly in each subject to minimize recording of the electrocardiogram. It was often necessary to ground this electrode or another EKG skin electrode on one extremity to eliminate electrical interference from outside sources. Simultaneous recordings of respiration and bowel contractions revealed artifacts produced in the electrical record from these sources. A thermistor in the nasal air-stream detected changes in air temperature with respiration that were recorded by a tele-thermom-

\footnotetext{
${ }^{1}$ Sanborn Co., Waltham, Mass.
} 


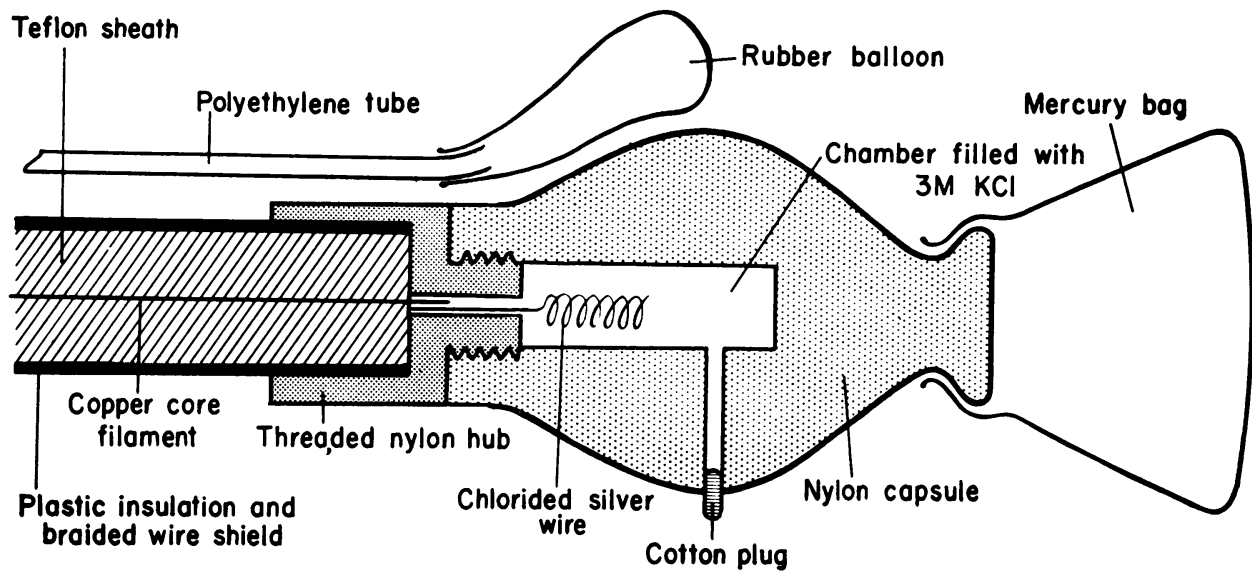

Fig. 1. Diagram of the SAlt-Bridge electrode.

eter 2 and Sanborn EKG preamplifier. The polyethylene tube transmitted pressure changes from the latex balloon to a Sanborn pressure transducer (model 267B), 1 driving a Sanborn carrier preamplifier (model 1503000).1 The outputs of these three activities were recorded on a Sanborn 4-channel recorder with a paper speed of $2.5 \mathrm{~mm}$ per second. We determined BER fre-

2 Yellow Springs Instrument Co., Yellow Springs, Ohio. quency by measuring the time required to complete 5 to 10 full cycles in continuity free of artifacts. The data were analyzed by standard statistical methods (16).

All subjects and patients fasted before study. The effect of fasting on BER frequency was evaluated in the normal group by studying 15 subjects after a 6 - to 10 hour fast and 22 subjects after an 11- to 16-hour fast. A 5\% dyclonine hydrochloride (Dyclone) spray was used to induce pharyngeal anesthesia, and some patients

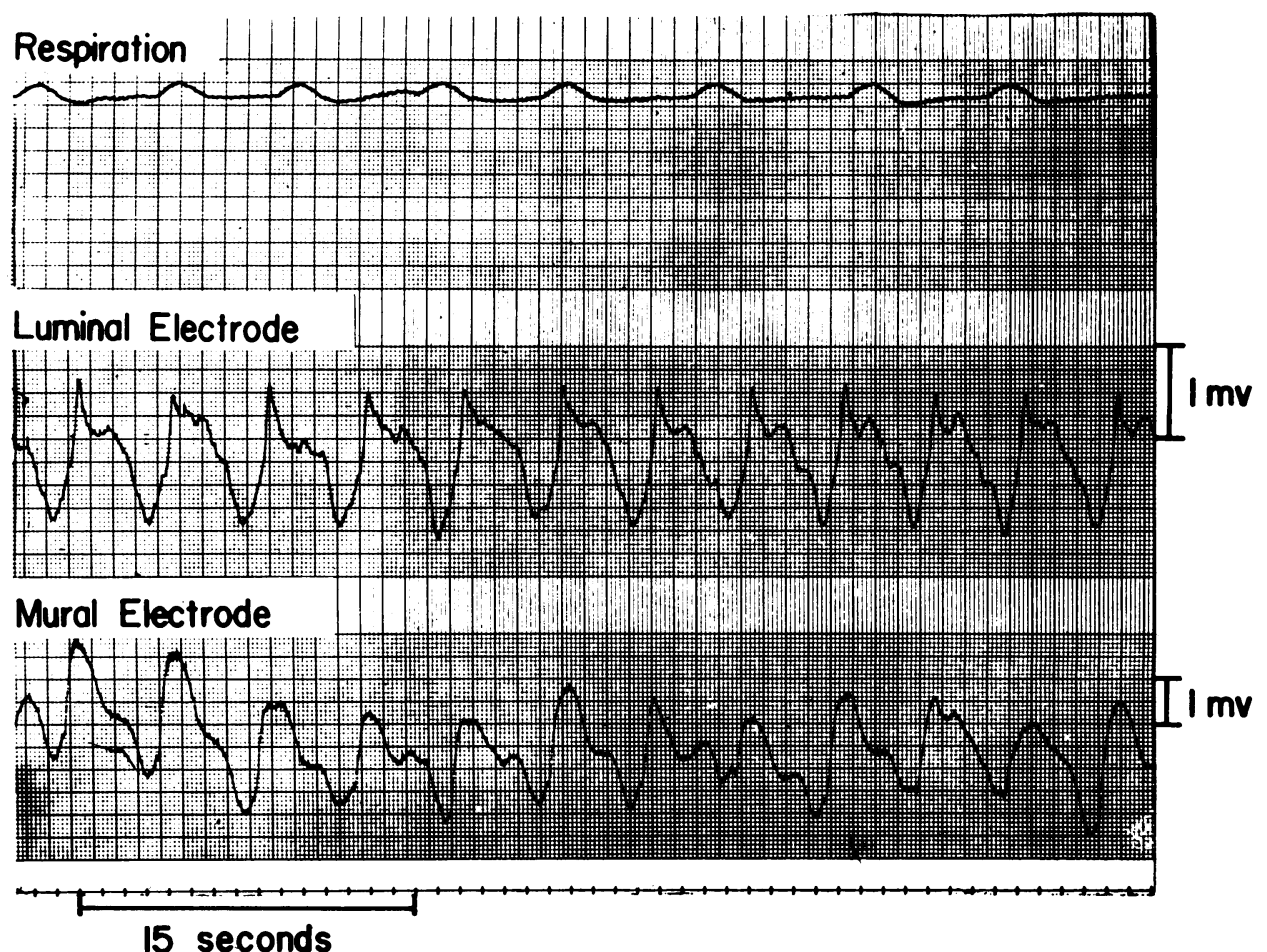

Fig. 2. Basic electrical RHythm (BER) in the dog Being ReCorded Simultaneously FROM THE SALT-BRIDGE EleCtrode (I.UMINAL ELECTRODE) AND A WIRE EI.ECTRODF. IMPLANTED OVER IT (MURAL ELECTRODE). 

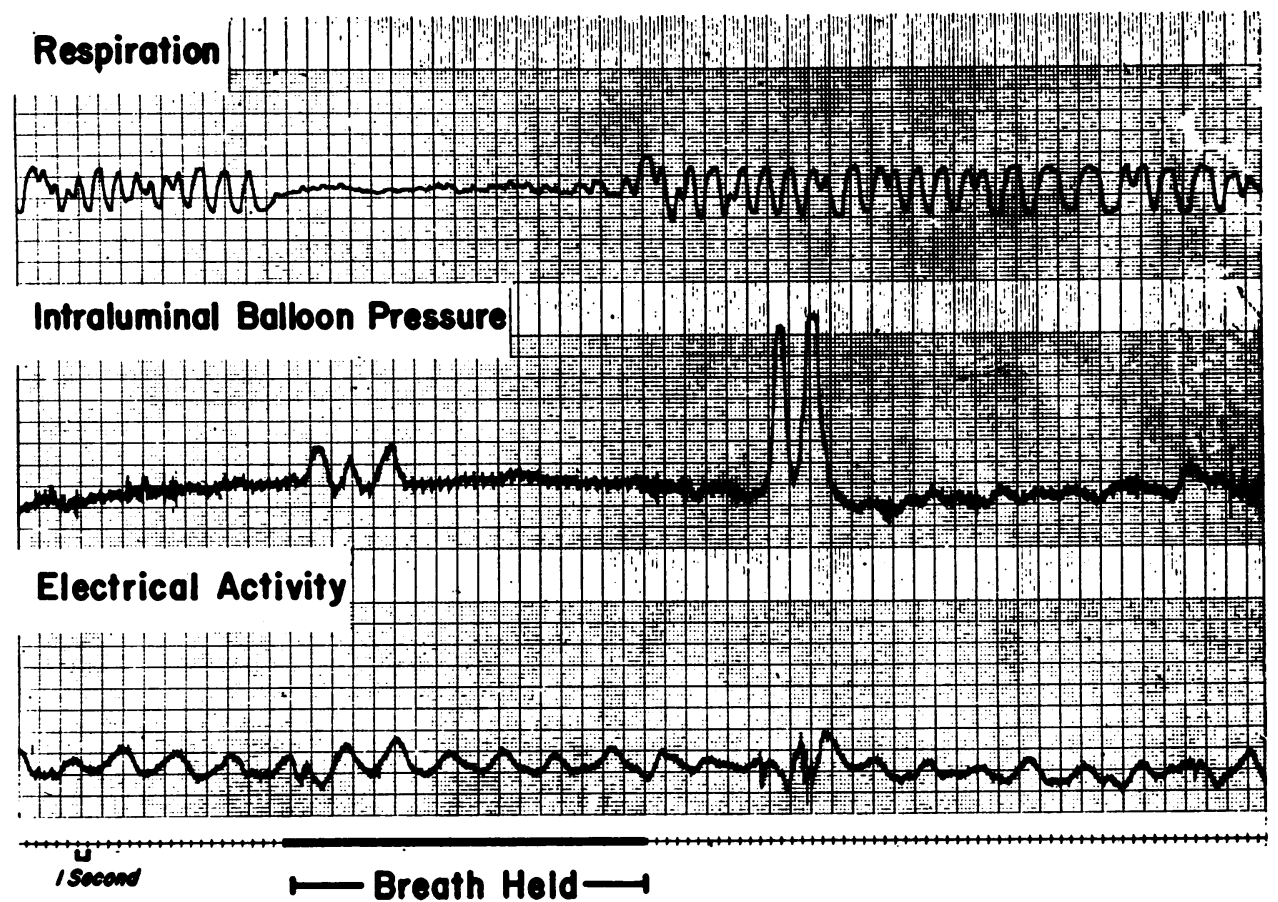

Fig. 3. Record showing duodenal BER. Three pressure peaks are shown on the balloon pressure record while respiration is suspended, and two peaks after respiration is resumed. Bursts of fast spikes occur preceding each of these contractions. The BER continues throughout the entire sequence. The EKG is present as a regular small spike on the electrical record, and the pressure record shows artifacts from the arterial pulse and from respiratory movements.

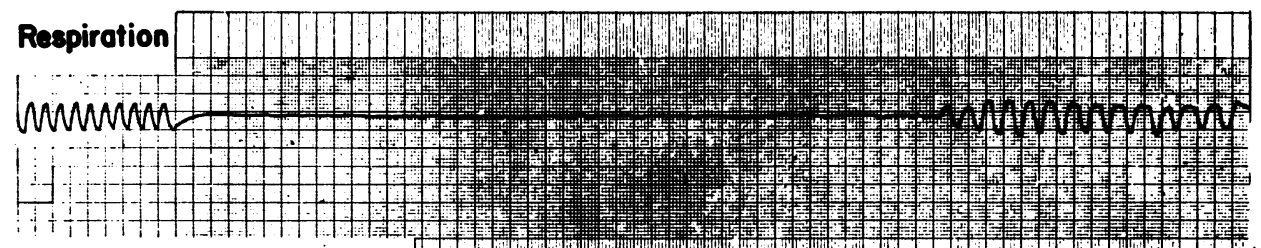

Intraluminal Balloon Pressure

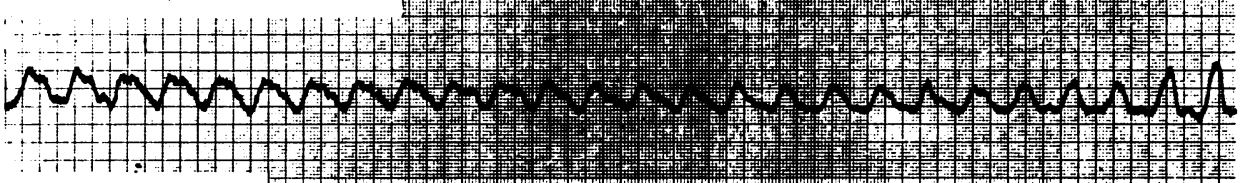

Electrical Activity

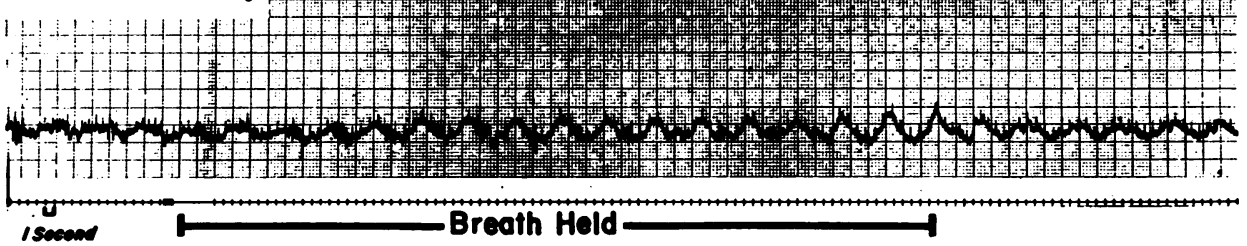

Fig. 4. Record showing spontaneous rhythmic duodenal contractions. During a period of rhythmic contractions a burst of fast spikes occurs on the descending limb of each cycle of the BER. Artifacts from the EKG and arterial pulse are present on the electrical and pressure records. 


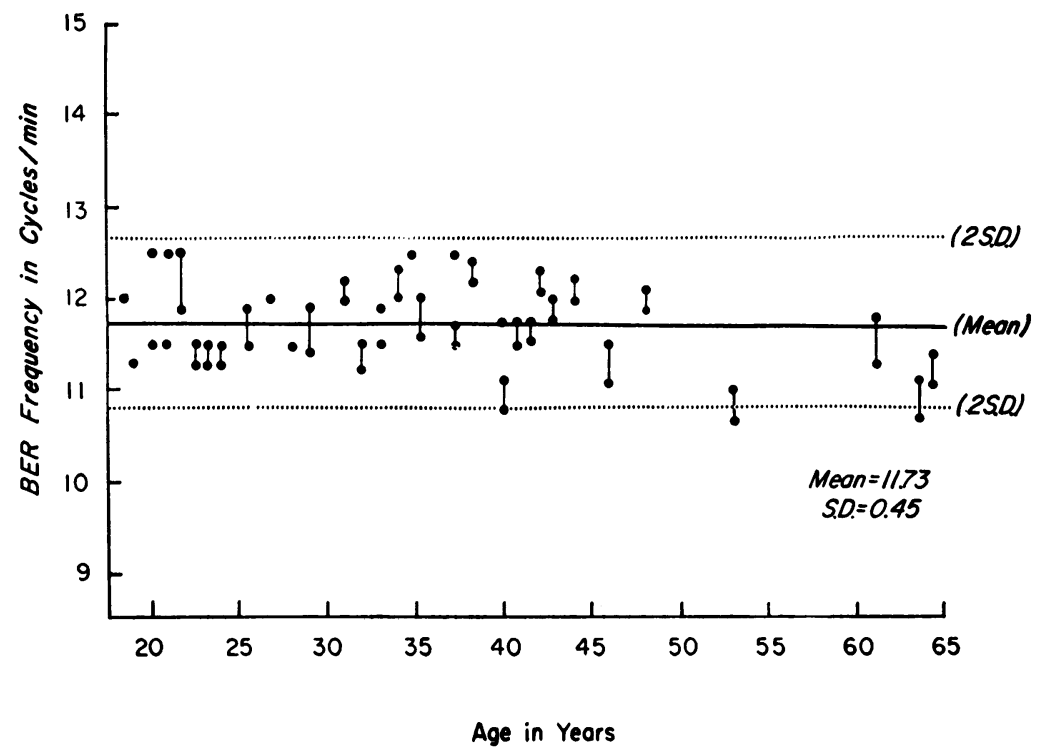

Fig. 5. BER Frequenctes in 37 nORMaL subJects.

with severe thyrotoxicosis were given $100 \mathrm{mg}$ of sodium pentobarbital parenterally 1 hour before the study. Four subjects from the normal group were studied before and after intravenous sodium pentobarbital. In some normal subjects the electrode was moved during a study to record BER frequency at several sites in the duodenum. The location of the electrode was estimated fluoroscopically in each case, and the site of recording classified as follows: if the electrode was transverse or showed only a slight downward turn, the site was recorded as upper duodenum; if the electrode was deflected downward for 3 or 4 inches but lay on the right side of the spine, the site was recorded as middle duodenum; if the electrode crossed to the left side of the spine so that the tip lay behind the stomach, the site was recorded as the lower duodenum. With the electrode in the first position it was sometimes difficult to tell whether it lay in the duodenum or gastric antrum. The electrical rhythm usually indicated the position in this event: in the antrum we detected a biphasic wave with a frequency of 3 per minute, whereas we recorded a monophasic wave at 11 to 12 per minute with the electrode in the duodenum.

In order to demonstrate that the intraluminal electrode accurately records the $\mathrm{BER}$, simultaneous records of small intestinal electrical activity were made from intraluminal and intramural electrodes. These studies were acute experiments in dogs. The salt-bridge electrode was placed in the lumen of the exposed dog small intestine and a wire electrode implanted in the muscle layer overlying the point of electrical contact of the intraluminal electrode with the mucosa, i.e., the cotton plug.

\section{Results}

Figure 2 shows a typical record from one preliminary experiment in a dog. Respiration is re- corded at the top from a thermistor placed in the nasal air-stream, with electrical activity from the salt-bridge electrode in the middle and from the implanted wire below. It is evident that the intraluminal electrode is recording electrical activity simultaneously with the intramural electrode.

Typical records from human subjects are shown in Figures 3 and 4 . In Figure 3 there are several bursts of fast spikes associated with rises of balloon pressure. In Figure 4 the bowel is contracting rhythmically at the frequency of the BER. Bursts of fast spikes are superimposed on the BER.

Figure 5 shows the duodenal BER frequencies in 37 normal adults arranged by age. In most subjects the frequency fluctuates within a narrow range. In this and following figures a solitary dot indicates a constant rate in a single subject, whereas two dots connected by a line indicate a range of frequencies in a single subject. The mean BER frequency in this group, calculated from the mean BER frequency for each subject, is 11.73 cycles per minute ( $\mathrm{SD} \pm 0.45$ cycles per minute, $\mathrm{SE} \pm 0.074$ cycles per minute). The broken horizontal lines in Figure 5 indicate $2 \mathrm{SD}$ from the mean. Inspection of Figure 5 suggests that there may be a slight decrease in mean BER frequency in older subjects.

The mean BER frequencies at the three duodenal sites are shown in Table I. When compared by the $t$ test these three means are not sig- 


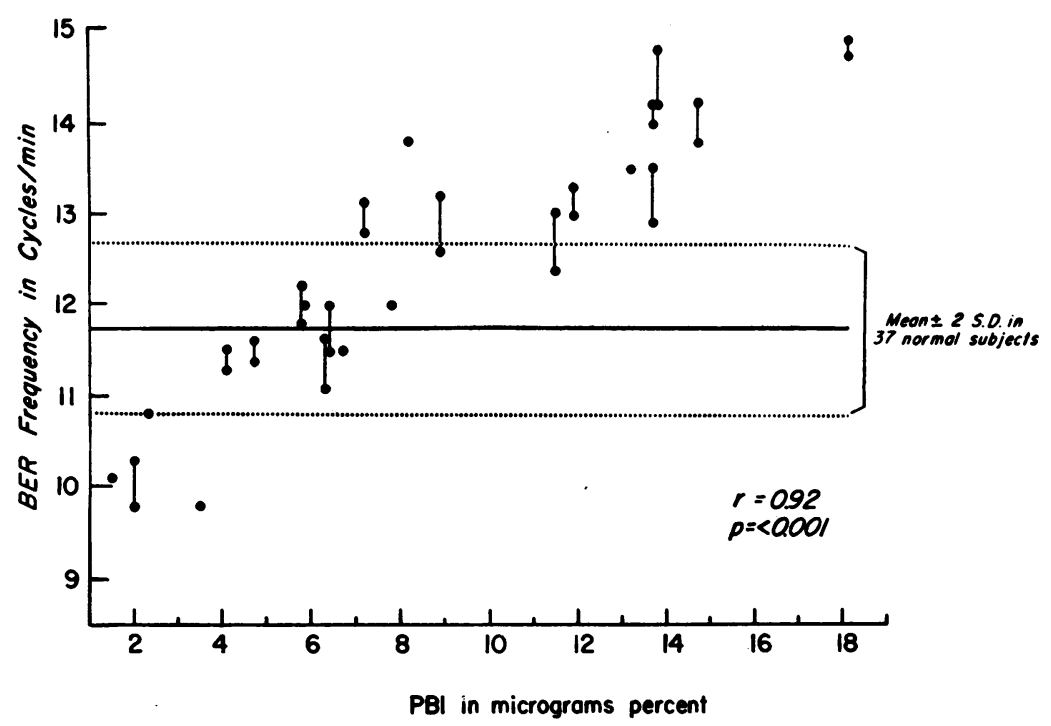

Fig. 6. BER FREQUENCY AND SERUM PROTEIN-BOUND IODINE (PBI) CONCENTRATIONS IN PATIENTS EVALUATED FOR THYROID FUNCTION.

nificantly different from one another (upper/ lower, $\mathrm{p}=0.9$; upper/middle, $\mathrm{p}=0.2$; middle/ lower, $\mathrm{p}=0.2$ ), in agreement with the observation in animals that BER frequency is the same throughout duodenum and upper jejunum.

The duration of fasting had no effect on the BER. In the group that fasted 6 to 10 hours the mean BER frequency was 11.79 ( $\mathrm{SD} \pm 0.48, \mathrm{SE}$ $\pm 0.12)$, and in the group that fasted 11 to 16 hours the mean BER frequency was 11.69 ( $\mathrm{SD} \pm$ $0.43, \mathrm{SE} \pm 0.09)$. These two means are not significantly different $(p=0.5)$. Intravenous sodium pentobarbital did not influence BER frequency.

Figure 6 shows the relationship between BER frequency and serum protein-bound iodine concentration $(\mathrm{PBI})$ in the patients evaluated for thyroid disease. The correlation coefficient is 0.92 ( $p<$ $0.001)$. PBI determinations were done in the clinical laboratories of the University Hospitals, where the normal range of values is from 3.5 to $8.0 \mu \mathrm{g}$ per $100 \mathrm{ml}$. In this and in the following figure containing data from patients the transverse lines indicate the mean and $2 \mathrm{SD}$ from the mean determined in the group of normal subjects. Figure 7 shows the BER frequencies arranged according to the 24-hour thyroidal uptake of $\mathrm{I}^{131}$. The correlation coefficient is 0.93 ( $p<0.001)$. This test was performed in the Radiation Research Laboratory, where the normal range of values is from 15 to $45 \%$. PBI determinations were available for 23 patients and $\mathrm{I}^{131}$ uptakes for 18 . Only 9 patients had basal metabolic rates measured, and the correlation coefficient with the BER is 0.8 $(\mathrm{p}<0.01)$.

\section{Discussion}

A recent review thoroughly discusses the characteristics of the electrical pattern of the intact intestinal muscle (17). One component of this pattern, a constant sinusoidal wave, is commonly called the slow wave or the basic electrical rhythm (BER). In the intact dog the BER appears to originate near the common bile duct (3) and is transmitted caudally through the longitudinal layer of smooth muscle. If electrodes are placed radially in the duodenum, the wave reaches all electrodes simultaneously (9), indicating that it is transmitted as an advancing ring with all points in cross-section in phase. An interesting charac-

TABLE I

Mean basic electrical rhythm (BER) frequencies at three duodenal sites

\begin{tabular}{lcccc}
\hline \hline \multicolumn{1}{c}{ Site } & $\begin{array}{c}\text { No. of } \\
\text { observa- } \\
\text { tions }\end{array}$ & $\begin{array}{c}\text { Mean } \\
\text { BER } \\
\text { frequency }\end{array}$ & SD & SE \\
\hline Upper duodenum & 12 & 11.80 & \pm 0.46 & \pm 0.133 \\
Middle duodenum & 15 & 11.77 & \pm 0.45 & \pm 0.116 \\
Lower duodenum & 14 & 11.55 & \pm 0.39 & \pm 0.104
\end{tabular}




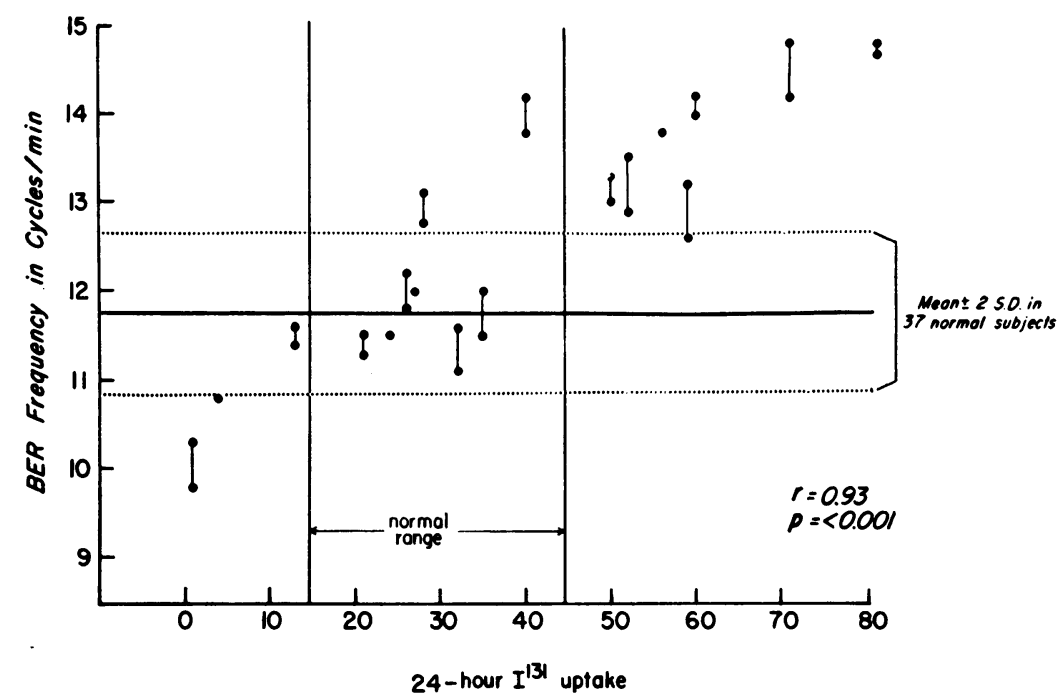

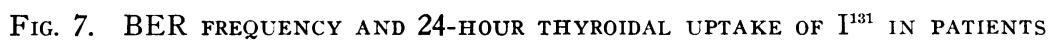
EVALUATED FOR THYROID FUNCTION.

teristic of the BER is the constancy of its rate. The frequency is 17 to 20 cycles per minute in the $\operatorname{dog}$ duodenum (17). This frequency is not significantly affected by nicotine $(7)$, hexamethonium $(2,7)$, atropine $(5,7)$, methantheline $(2,5)$, neostigmine $(2,5,7)$, physostigmine $(5,7)$, tetraethylammonium chloride (5), Dibenzyline, dichloroisopropyl norepinephrine (7), or barbiturate anesthesia (5). The frequency is increased by large doses of catecholamines (18) and is usually slowed by morphine $(7,9)$. Acetylcholine seems to have little or no effect on BER frequency $(5,7)$. In contrast to the unresponsiveness of the frequency to a variety of drugs, the $\mathrm{BER}$ frequency is sensitive to changes in temperature $(6,7)$, a reduction of body temperature of $10^{\circ} \mathrm{C}$ in the dog reducing the frequency to less than $50 \%$. BER frequency is also reduced by hypoxia $(5,6)$ and by ether anesthesia $(1,3)$. The latter effect may represent a direct effect of ether but is more likely secondary to lowered body temperature or to hypoxia (7). The BER frequency increases in isolated tissue bathed in solutions with high calcium concentrations (14) and falls when calcium concentration is reduced (13).

Normal BER frequencies have not been determined accurately because of limitations imposed by the methods heretofore available. Most animal studies have used needle or wire electrodes inserted into the small bowel exposed during op- erations, and changes in tissue temperature or in tissue oxygenation were not controlled. The use of Biebl loop dogs (9) probably avoids some of these variables, but these preparations cannot be considered normal. Most previous studies in man have been made with intramural electrodes placed in the exposed duodenum (8), or in ileal buds and ileal bladders $(5,7,8)$. Techniques, as in the present study, using intraluminal electrodes avoid variables introduced by anesthesia and surgical manipulation. Holaday, Volk, and Mandell (5) recorded the BER from the lumen using electrodes attached to the surface of an inflated balloon. They performed eight satisfactory studies in man but did not calculate BER frequencies. Daniel, Honour, and Bogoch (6) observed slowing of BER transmission across such an inflated balloon, and it is possible that the recorded BER frequency might be altered.

We have found that the intraluminal electrode faithfully records the BER (Figure 2), and others have confirmed this (12). It is apparent that the form of the wave differs slightly in the two recording techniques. This difference in form may be explained partly by the observation of Bortoff (11) that the form of the slow wave recorded from a capillary glass electrode separated about $1 \mathrm{~mm}$ from the serosal surface of the intestine immersed in Tyrodes solution approximates the second time derivative of the slow wave recorded 
from an intracellular electrode in the longitudinal muscle layer. In another experiment we have recorded from the salt-bridge electrode placed on the opened dog jejunum in such a way that it makes contact with the mucosa only through a $1-\mathrm{cm}$ length of saline-soaked cotton wick. The form of the wave recorded in this way resembles that shown by Bortoff (11) as recorded from the capillary electrode separated from the serosa by $1 \mathrm{~mm}$. Thus it appears that an intimate contact of the electrode with mucosa is not necessary for qualitative recording of the BER but that the form of the wave may be determined by the distance that separates the silver silver-chloride junction from the source of the BER. Spontaneous variations occur in the form of the slow wave from time to time during our studies, and these may be due to slight shifts of the electrode toward or away from the mucosa.

Artifacts may seriously complicate the interpretation of records obtained by our method. Often these artifacts are waves, highly variable in form, at the frequency of respiration. Since these cease when the breath is held, we attribute them to shifts in electrode position induced by movement of the viscera with respiratory movements. They are easily eliminated by suspension of respiration, and BER rates are usually calculated during such intervals. Other artifacts occur as sudden irregular shifts of base line. Such artifacts usually occur when the balloon pressure record is showing contractile activity, so that we attribute these to electrode movement resulting from such activity. Long periods may occur free of this artifact, however, allowing calculation of BER frequency. Such periods sometimes occur even during rhythmic contractions of the intestine as shown in Figure 4. In this instance the waves recorded in the electrical record could conceivably be movement artifact, but this seems unlikely in view of their regularity and uniformity.

The sudden bursts of fast spikes that often immediately precede the balloon pressure peaks as shown in Figures 3 and 4 are fairly consistent in form and in their relationship to pressure peaks and do not resemble the gross and irregular patterns that are artifacts resulting from electrode movement. In their form and in their temporal relationship to balloon pressure peaks these fast spikes resemble the fast spikes described with other methods of recording. We have recorded these fast spikes simultaneously from intraluminal and intramural electrodes in the exposed small bowel of the dog and believe that they are the action potentials of contracting smooth muscle.

Our observations indicate a high degree of correlation between the duodenal BER frequency and the level of thyroid function. Thus, the availability of energy from cellular metabolic processes as influenced by the state of thyroid activity is a major factor governing this frequency, and the source of the frequency must be closely coupled to cellular oxidation. Most early investigators thought that the BER originated in the intrinsic nerve plexuses of the intestine. The insensitivity of the rhythm to autonomic drugs led to the suggestion that it is myogenic. Daniel, Honour, and Bogoch (6) and Bortoff (11), using intracellular microelectrodes, have shown that the cells of the longitudinal layer are undergoing cyclic oscillations in resting potential at the frequency of the externally recorded $B E R$, indicating that this rhythm is indeed myogenic. The BER is an example of the spontaneous subthreshold fluctuations in membrane potential seen in a variety of smooth muscles (19). If the BER has its origin in the spontaneous fluctuations of smooth muscle membrane potential, it must reflect rhythmic changes in the mechanisms that maintain this potential. These mechanisms are not understood and seem to be different in smooth muscle and skeletal muscle. Although the precise mechanisms that are responsible for the oscillating transmembrane potential of smooth muscle are unknown, they clearly include depolarizing forces and repolarizing forces, constantly opposing each other in such a manner that one alternately exceeds the other. The rate of energy supply must be most important in this balance of forces. If the BER reflects these membrane potential oscillations, it must be dependent upon this source of energy and should change with changes in the rate of energy supply. The effects of temperature and hypoxia on BER frequency also indicate that the BER responds to changes in the availability of energy by changes in its frequency. Furthermore, the BER frequency is reduced by low concentrations of dinitrophenol (11). 
Although there are no reported measurements of BER frequency in animals made hypermetabolic with thyroid hormones, observations have been reported on maximal small intestine contraction rates in such animals. Oppenheimer and Glyer (20) observed no change in the frequency of spontaneous rhythmic contractions of the intestine in dogs made hypermetabolic with desiccated thyroid. Castleton and Alvarez (21), on the contrary, saw an increase in maximal contraction rate of the intestine in rabbits made hypermetabolic with thyroxin. Although these investigators were not recording BER frequency, inferences regarding $B E R$ frequency may be drawn from observations of the maximal rate of rhythmic contraction, since these two frequencies are the same in the small bowel (16).

The remarkable consistency of the frequencies recorded in normal subjects emphasizes the stability of the controlling factors. Probably a number of minor factors affecting frequency cause the variations in the group of normal subjects. The duodenal BER frequency is not perfectly constant in each individual but varies up to 0.5 cycle per minute. Thus, variable factors produce minor variations of frequency in the individual. The studies of McCoy and Bass (18) suggest that circulating catecholamines at very high levels may be one such factor.

The correlation between BER frequency and other measures of thyroid activity suggests the use of this measurement as another index of thyroid function. The frequency is not greatly influenced by factors other than oxygenation, temperature, and metabolic rate. Measurement of the frequency, however, is technically more difficult than the standard thyroid function tests. It might prove useful in those patients in whom other tests of thyroid function are not reliable.

\section{Summary}

We have constructed an intraluminal salt-bridge electrode to record the spontaneous electrical activity of the duodenum in ambulatory human subjects. The two characteristic components of this activity were identified: 1) a constant sinusoidal wave, the duodenal slow wave or basic electrical rhythm, and 2) irregular bursts of fast spikes associated with segmental duodenal contractions.
The mean frequency of the duodenal basic electrical rhythm in 37 healthy subjects was 11.73 cycles per minute $(\mathrm{SD} \pm 0.45, \mathrm{SE} \pm 0.074)$. The frequency of the rhythm in 24 patients evaluated for thyroid disease varied widely and showed a close positive correlation with the state of functional thyroid activity as determined by standard clinical indexes of thyroid function. These findings establish that the availability of energy from cellular metabolic processes is a major factor governing the frequency of the duodenal basic electrical rhythm.

\section{Acknowledgments}

We are grateful to the members of the Thyroid Clinic of the State University of Iowa Hospitals and to the administration of the Iowa State Penitentiary for making available the subjects and patients used in this study.

\section{References}

1. Puestow, C. B. The activity of isolated intestinal segments. Arch. Surg. 1932, 24, 565.

2. Milton, G. W., A. W. M. Smith, and H. I. O. Armstrong. The origin of the rhythmic electropotential changes in the duodenum. Quart J. exp. Physiol. $1955,40,79$.

3. Milton, G. W., and A. W. M. Smith. The pacemaking area of the duodenum. J. Physiol. (Lond.) 1956, 132, 100.

4. Armstrong, H. I. O., G. W. Milton, and A. W. M. Smith. Electropotential changes of the small intestine. J. Physiol. (Lond.) 1956, 131, 147.

5. Holaday, D. A., H. Volk, and J. Mandell. Electrical activity of the small intestine with special reference to the origin of rhythmicity. Amer. J. Physiol. 1958, 195, 505.

6. Daniel, E. E., A. J. Honour, and A. Bogoch. Electrical activity of the longitudinal muscle of dog small intestine studied in vivo using microelectrodes. Amer. J. Physiol. 1960, 198, 113.

7. Daniel, E. E., B. T. Wachter, A. J. Honour, and A. Bogoch. The relationship between electrical and mechanical activity of the small intestine of dog and man. Canad. J. Biochem. 1960, 38, 777.

8. Daniel, E. E., D. R. Carlow, B. T. Wachter, W. H. Sutherland, and A. Bogoch. Electrical activity of the small intestine. Gastroenterology 1959, 37, 268.

9. Bass, P., C. F. Code, and E. H. Lambert. Motor and electric activity of the duodenum. Amer. J. Physiol. 1961, 201, 287.

10. Berkson, J., E. J. Baldes, and W. C. Alvarez. Electromyographic studies of the gastrointestinal tract. I. The correlation between mechanical movement and changes in electrical potential during rhythmic 
contraction of the intestine. Amer. J. Physiol. 1932, 102, 683.

11. Bortoff, A. Slow potential variations of small intestine. Amer. J. Physiol. 1961, 201, 203.

12. Garrett, J. M., J. F. Schlegel, and H. N. Hoffman II. Intraluminal detection of intestinal electrical activity. Fed. Proc. 1963, 22, 225.

13. Bortoff, A. Electrical activity of intestine recorded with pressure electrode. Amer. J. Physiol. 1961, 201, 209.

14. Ambache, N. The electrical activity of isolated mammalian intestines. J. Physiol. (Lond.) 1947, 106, 139.

15. Bozler, E. The relation of the action potential to mechanical activity in intestinal muscle. Amer. J. Physiol. 1946, 146, 496.

16. Hill, A. B. Principles of Medical Statistics. New York, Oxford University Press, 1961.
17. Daniel, E. E., and K. M. Chapman. Electrical activity of the gastrointestinal tract as an indication of mechanical activity. Amer. J. dig. Dis. 1963, 8, 54.

18. McCoy, E. J., and P. Bass. Chronic electrical activity of gastroduodenal area: effects of food and certain catecholamines. Amer. J. Physiol. 1963, 205, 439.

19. Burnstock, G., M. E. Holman, and C. L. Prosser. Electrophysiology of smooth muscle. Physiol. Rev. 1963, 43, 482.

20. Oppenheimer, M. J., and N. M. Glyer. The effect of elevated metabolism on rate of intestinal contractions. Amer. J. dig. Dis. 1941, 8, 471.

21. Castleton, K. B., and W. C. Alvarez. The rate of rhythmic contraction of the small bowel of rabbits as influenced by experimentally produced hyperthyroidism. Amer. J. dig. Dis. 1941, 8, 473. 